\title{
AN OUNCE OF PREVENTION
}

\author{
by Bernard Dixon
}

\section{$\mathrm{H}$}

ere's a sobering paradox for those in the health care industry. Largely through ingenious applications of molecular biology, we are today seeing the most exciting and fundamental advances ever achieved in the understanding, diagnosis, and treatment of disease. Yet at the same time, medicine faces an uneasy present and an uncertain future. Quite apart from socially founded problems such as the growth of malpractice suits in many countries, and the inequitable consequences of organizing medicine principally as a profit-centered business, there are five additional concerns.

First, iatrogenic disease is increasing. Second, there is an indefensible emphasis on therapy rather than prevention. Third, health spending is being distorted so that disproportionate sums are going into (sometimes heroic) measures to prolong the last months of life. Fourth, problems such as cardiovascular disease and cancer, whose avoidance and conquest have much to do with lifestyle, are persisting long after we might have expected more spectacular rewards from high-tech intervention. And on a world scale, decent sanitation and nutrition remain far more important than even the most potent drugs and vaccines.

No, this is not an analysis plucked out of one of those books, published during the $1960 \mathrm{~s}$, that denigrated the worth of science-based medicine, argued that psychiatric illness was a myth, and indicated that we would all enjoy rude good health if we drank camomile tea for breakfast every morning. It is a serious suggestion, triggered in part by reading a remarkable chapter by Howard Rasmussen of the Yale School of Medicine in Biology and Medicine in the 21st Century (edited by M.A. Hardy \& R.K.H. Kinne and published recently by Karger). Much of Rasmussen's chapter is devoted to disordered cell communication as the basis of disease - one of those fields being ploughed so frenetically and successfully by molecular biologists. Yet he concludes by highlighting the limitations of this approach and arguing for a much wider perspective on illness and health.

Although cell signaling is an areain which Rasmussen himself has made major contributions, he reminds us that signaling pathways and the classes of receptors linked to them are a shared attribute of many differentcell types. Thisindicates the need for caution with regard to the possibility of deploying receptorspecific, tissue-selective drugs to treat conditions expressing altered plasma membrane dialogues. Equallyimportant are the fact that many multiple extracellular signals occur in specific sequences over time, and the recognition that the development of vascular disease and the emergence of neoplasia are historical processes.

"These insights argue strongly for an equal or greater focus of medical interest on understanding the initial causes of the historical processes involved in the evolution of chronic disease," Rasmussen concludes. "Major targets for this interest must be the environmental, dietary, and behavioral factors which impact on genetically susceptible individuals, on the one hand, and the nature of the initial derangement in signaling events which begins the historical process at the cellular level on the other."

Of several evidences he could have adduced for the contemporary distortion of priorities in medicine, Howard Rasmussen chooses a contentious one-the greater and greater percentage of the health care dollar now being allocated to the treatment of people in the last 12 months of their lives. "This means that of all the dollars, physicians' time, and other health care resources devoted to a person's health care throughout his lifetime, nearly as many are being spent to prolong the last year of his life as are being spent to promote health up until his last year."

Now let us turn to the old English city of Southampton for news of an unusual research project which, though not mentioned by Rasmussen, nevertheless adds an extra dimension to his thesis. Around the mid-1980s, David Barker and colleagues in the Medical Research Council's Environmental Epidemiology Unit at the University of Southampton began to investigate the striking correlation they had noticed between areas of Great Britain with high mortality from ischaemic heart disease and stroke, and those that had experienced high infant mortality rates earlier in the century. Was it possible that factors adversely affecting infant health "programmed" people for subsequent disease?

As reviewed by one of Barker's colleagues, Christopher Martyn, during this year's Edinburgh International Science Festival, that hypothesis is beginning to look extremely convincing. Establishing their own case, and defending it against skeptical opposition, has rested on longitudinal studies in which the Southampton investigators have moved from populations to comparisons of individuals over more than half a century. Records kept by some remarkably punctilious midwives and health visitors in the early decades of this century have provided essential data for this work.

In a series of papers published during the past two years, the MRC team has established that fetal growth, and growth and nutrition in infancy, have marked effects on cardiovascular risk factors later in life, including blood pressure, and plasma levels of cholesterol, fibrinogen, and apolipoprotein B. Their most recent study (British Medical Journal 304:801, 1992) indicates that the age of weaning and method of infant feeding influence serum cholesterol and ischemic heart disease mortality in adulthood. Parallel investigations have shown that fetal and infant well-being are reflected in diabetes and abnormal glucose tolerance later in life. Other data link chronic bronchitis in the adult with post-neonatal mortality.

Early life experience may be less well defined than any gene or receptor. Nevertheless, these are extremely powerful correlations, heavy with sociopolitical implications. Time to reassessour priorities?/// 